\title{
Математическое моделирование рабочих режимов дефлегматора абсорбционного водоаммиачного холодильного агрегата в системах получения воды из атмосферного воздуха с использованием солнечной энергии
}

\section{E. А. Осадчук, В. Х. Кириллов}

Одесская национальная академия пищевых технологий, Канатная, 112, Одесса, 65039

\begin{abstract}
Разработана математическая модель режимов пленочного течения с восходящим потоком паровой смеси с высокоэффективным отводом тепла в режиме вынужденной конвекции. Проведена оценка параметров пленочного течения жидкости и парового потока (скорости и числа Рейнольдса) для типичных значений диаметров труб дефлегматора 20, 32 и 40 мм. Показано, что режим пленочного течения ламинарный, а парового потока - развитый турбулентный, причем толщина пленки практически неизменна для рассматриваемых размеров труб дефлегматора.
\end{abstract}

Ключевые слова: пленочное течение по вертикальной стенке дефлегматора; абсорбционный водоаммиачный холодильный агрегат; гелиоколлектор.

\section{Математичне моделювання робочих режимів дефлегматора абсорб- ційного водоаміачного холодильного агрегату в системах отримання води з атмосферного повітря з використанням сонячної енергії}

\author{
Є. А. Осадчук, В. Х. Кирилов
}

Одеська національна академія харчових технологій, Канатна, 112, Одеса, 65039

Розроблено математичну модель режимів плівкової течії з висхідним потоком парової суміші з високоесективним відведенням тепла в режимі вимушеної конвекції. Проведено оцінку параметрів плівковоі течії рідини і парового потоку (швидкості і числа Рейнольдса) для типових значень діаметрів труб дефлегматора 20, 32 та 40 мм. Показано, що режим плівкової течії ламінарний, а парового потоку розвинений турбулентний, до того ж, товщина плівки практично незмінна для розглянутих розмірів труб дерлегматора.

Ключові слова: плівкова течія по вертикальній стінці дефрлегматора; абсорбчійний водоаммі-ачний холодильний агрегат; геліоколектор.

DOI: http://dx.doi.org/10.15673/ret.v53i1.534

(C) The Author(s) 2017. This article is an open access publication

This work is licensed under the Creative Commons Attribution 4.0 International License (CC BY) http://creativecommons.org/licenses/by/4.0/

\section{1 Введение}

Около 70 процентов поверхности земного шара покрыто водой, однако на 97,5 процента она состоит из соленой воды. Оставшиеся 2,5 процента приходятся на пресную воду, почти две трети которой находится в замороженном состоянии в ледниковых шапках. Между тем, основная часть пресной воды находится в 1 километровом слое атмосферы. По данным работы [1] средняя абсолютная влажность близ земной поверхно- сти составляет $11 \mathrm{r} / \mathrm{m}^{3}$, а в тропических регионах она доходит до 25 г/м ${ }^{3}$ и выше. Большое количество стран тропического пояса страдает от отсутствия пресной воды, хотя ее содержание в атмосфере весьма значительно. Поэтому одной из важнейших задач является развитее технологий, позволяющих извлекать воду из воздуха, причем непосредственно на месте, где она необходима [2]. Как показывает анализ [3], наибольшие перспективы имеют методы, связанные с работой генераторов искусственного холода - холодильных аг- 
регатов, которые обеспечивают температуру воздушного потока ниже температуры точки росы. В наше время, основной объем рынка оборудования по выделению воды из воздуха приходится на системы, имеющие в своём составе компрессионную холодильную установку с электрическим приводом, которая гарантированно обеспечивает температуру ниже точки росы.

Однако в мире насчитывается много мест, где помимо проблем с водой есть проблемы с электроэнергией. В связи с этим, необходимо уделить значительное внимание, теплоиспользующим холодильным установкам, источником тепла в которых является солнечная энергия.

Особый интерес среди таких теплоиспользующих холодильных систем представляют абсорбционные водоаммиачных холодильные агрегаты (АВХА), рабочим телом которых является раствор природных веществ: аммиака и воды - водоаммиачный раствор (BAP), не оказывающий неблагоприятное техногенное воздействие на экологию планеты [4]. В отличие от аналогов бромистолитевого типа, АВXА некритичны к изменению температур греющего источника и окружающей среды и могут работать в режиме воздушного охлаждения теплорассеивающих элементов [5]. Эти два фактора делают их крайне привлекательными для разработчиков автономных систем получения воды из атмосферного воздуха на базе солнечного излучения. В то же время в мировой практике до последнего времени отсутствовали такого типа разработки.

В последние годы разработчики ОНАПТ предложили целый ряд новых технических решений по созданию систем получения воды из атмосферного воздуха на базе ABXA, как насосного $[6,7]$, так и безнасосного типа [8].

Был выполнен многофакторный термодинамический анализ как насосных схем [9-11], так и безнасосных [9], который позволил определить основные энергетические характеристики АВХА при работе в широком диапазоне температур источника тепловой энергии и окружающей среды.

Анализ полученных результатов показал перспективность разработки, в первую очередь, насосных АВXА для систем получения воды из атмосферного воздуха, в том числе и в автономном режиме работы. Для работы насосов и систем автоматики в АВХА с холодопроизводительностью до 5 кВт требуется не более 200 Вт электрической энергии, которая может быть легко получена с помощью современных стандартных и недорогих фотоэлектрических солнечных панелей.

Безнасосные АВХА оказались критичными к уровню температур источника тепловой энергии (солнечного излучения). Было показано, что для их работы в условиях жаркого климата при температуре окружающей среды порядка $40^{\circ} \mathrm{C}$ температура в зоне подвода тепла (генераторе) должна быть не меньше $160^{\circ} \mathrm{C}$ [9]. Такая температура может быть достигнута при помощи вакуумных солнечных коллекторов, но это значительно удорожает конечную систему получения воды из атмо- сферного воздуха и существенно ограничит область применения.

Для разработки насосных АВХА в составе систем получения воды из атмосферного воздуха необходимо создать методику расчета конструктивных параметров элементов АВХА, которая бы учитывала особенности работы систем получения воды из атмосферного воздуха в части широты диапазона режимных параметров (при движении солнца по небосводу в течение светового дня). В настоящее время такая методика отсутствует.

В то же время одним из основных элементов ABXA, который в значительной мере определяет его работоспособность и энергетическую эффективность, является дефлегматор, который предназначен для очистки пара холодильного агента (аммиака) от пара воды [5] за счет разности нормальных температур кипения и, соответственно, преимущественной конденсации высококипящего компонента - воды. Теплота фазового перехода отводится в окружающую среду.

Дефлегматор АВХА в идеальном случае должен полностью отделить аммиак от воды, что представляет собой некоторую техническую проблему из-за достаточно близких, с позиции техники и технологии разделения, нормальных температур кипения (минус $34^{\circ} \mathrm{C}$ и $100^{\circ} \mathrm{C}$ у аммиака и воды, соответственно [12]).

Так, в случае интенсивного отвода тепла от наружной поверхности дефлегматора одновременно с конденсацией пара воды будет конденсироваться и пар аммиака. Соответственно в конденсатор и испаритель снизится подача аммиака, а это приведет к снижению холодопроизводительности АВХА.

В другом случае, при вялотекущем теплообмене стенок дефлегматора с окружающей средой водяной пар не полностью будет конденсироваться в дефлегматоре. Часть его вместе с паром аммиака будет поступать в конденсатор и далее в испаритель. С учетом того, что пар аммиака из испарителя удаляется за счет процесса абсорбции его слабым ВАР, то наличие даже незначительного количества воды в жидком аммиаке приведет к снижению интенсивности процессов тепломассообмена как в испарителе, так и в абсорбере, что приведет и к снижению холодопроизводительности ABXA.

Задача идеального или близкого к нему процесса очистки пара аммиака в безнасосных АВХА традиционно решается путем частичной [13] либо полной [14] теплоизоляции начального (по паровому потоку) участка дефлегматора. Наибольший эффект достигается за счет применения оригинальных способов регулирования подводимой тепловой нагрузки в генераторе АBXА при одновременном контроле температур в характерных точках дефлегматора $[15,16]$.

Имеющийся опыт моделирования тепловых режимов дефлегматоров безнасосных АBXА [17] не может быть применен для расчета насосных схем ABXА из-за существенного (как минимум на два порядка) различия режимных параметров в части расхода потоков и размеров конструкции. 


\section{2 Моделирование рабочих режимов дефлегма- тора абсорбционного водоаммиачного холо- дильного агрегата}

В основу математической модели была положена функциональная схема насосного АBXА, предложенная в оригинальном авторском техническом решении [6]

Гелеоколлектор 1 и ресивер крепкого (по содержанию аммиака) ВАР 4 представляют собой сообщающиеся сосуды и находятся под уровнем $\nabla 1$. К гелеоколлектору 1 подводится тепловое солнечное излучение $\mathrm{Q}_{c}$ и из крепкого ВАР выпаривается преимущественно низкокипящий компонент (аммиак). Гелиоколлектор 1 расположен под некоторым углом к горизонту для максимального поглощения теплового солнечного излучения, причем угол наклона устанавливается в зависимости от широты местности.

Образовавшиеся пузырьки пара проталкивают в верхнюю часть гелиоколлектора 1 обедненный по аммиаку (слабый) ВАР, который сливается в ресивер 3, а паровая водоаммиачная смесь поступает в вертикальный дефлегматор, где с отводом теплоты в окружающую среду конденсируется преимущественно пар воды. Образующаяся флегма стекает обратно в ресивер 3. Из дефлегматора 2 очищенный пар аммиака при помощи бустер-компрессора 5 сжимается до давления $\mathrm{P}_{k}$ и направляется в конденсатор 6. Соответствующим уровнем давления $\mathrm{P}_{\mathrm{k}}$ создается необходимый перепад температур для процесса конденсации с отводом тепла $Q_{\mathrm{k}}$ в окружающую среду. Из конденсатора 6 жидкий аммиак дросселируется в вентиле 7 до давления $\mathrm{P}_{0}$ В испарителе 8 и абсорбере 9. В испарителе 8 аммиак кипит при давлении $P_{0}$ и температуре $T_{0}$ с отводом теплоты $Q_{0}$ от объекта охлаждения (потока наружного воздуха).

Температура $T_{0}$ в системах получения воды из атмосферного воздуха поддерживается ниже температуры точки росы $T_{\mathrm{p}}$ наружного воздуха, в связи с чем из воздуха выпадает конденсат, при этом и сам воздушный поток охлаждается.

Постоянное пониженное давление $P_{0}$ в испарителе поддерживается за счет постоянного поглощения в абсорбере пара аммиака потоком слабого ВАР, который, в свою очередь, поступает в абсорбер 9 из ресивера 3 через дроссельный вентиль 11. Образовавшийся в абсорбере 9 после поглощения аммиака крепкий ВАР циркуляционным насосом 10 подается обратно в ресивер 4 и цикл повторяется. Для повышения энергетической эффективности в такой схеме, как правило, устанавливают двухпоточный регенеративный теплообменник потоков крепкого и слабого ВАР, циркулирующих между абсорбером и гелиоколлектором.

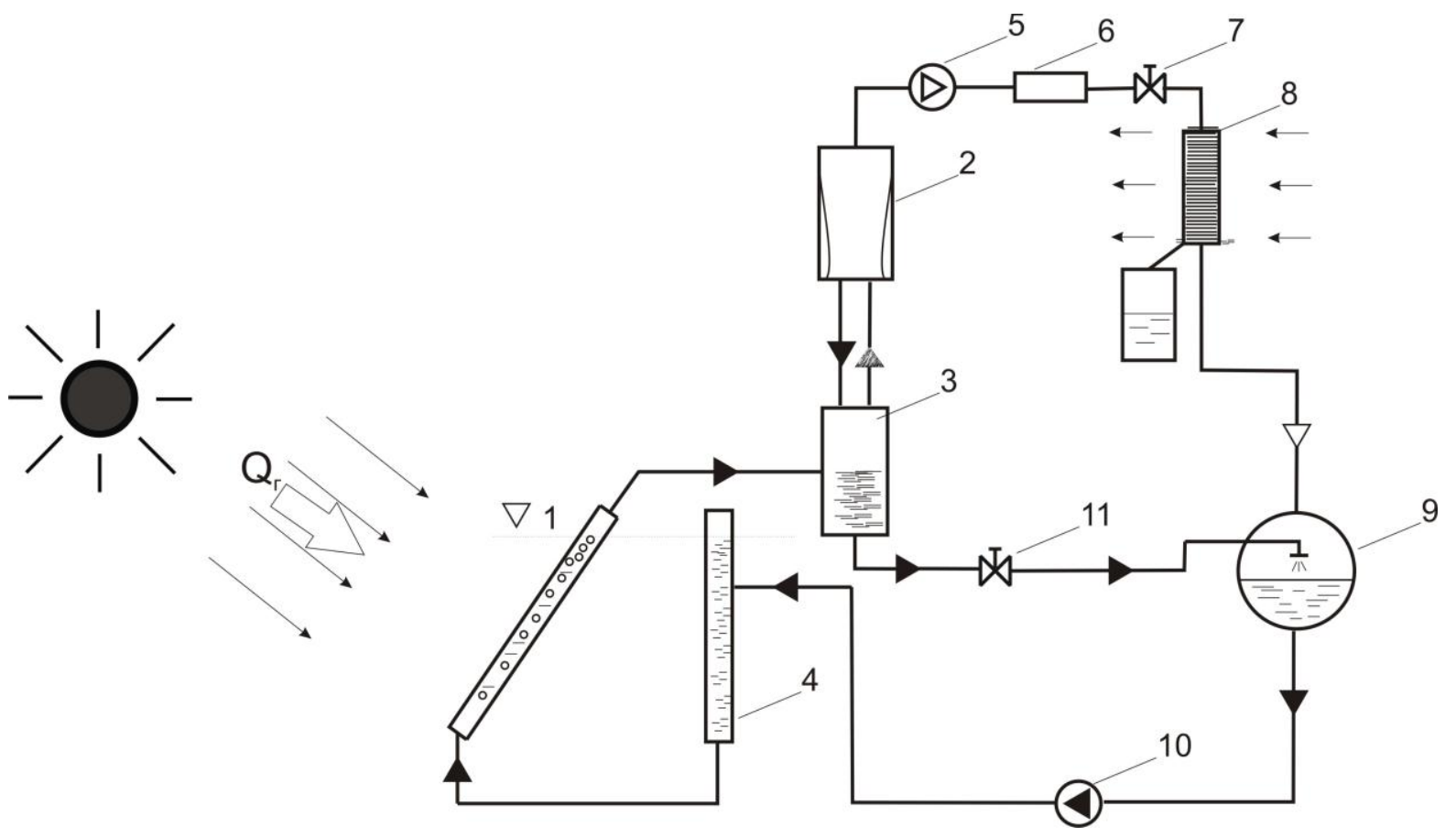

Рисунок 1 - Схема установки для получения воды из атмосферного воздуха:

1 - гелиоколлектор; 2 - дефлегматор; 3 - отделитель жидкости; 4 - ресивер крепкого ВАР; 5 - бустеркомпрессор; 6 - конденсатор холодильного агента (аммиака); 7 - дроссель жидкого аммиака; 8 испаритель; 9-абсорбер; 10 - насос крепкого ВАР; 11 - дроссель слабого ВАР

В рассматриваемом разделе предлагается теоретический расчёт генераторного узла на основе математического моделирования процессов конденсации паров воды и частично паров аммиака на внутренней поверх- ности подъёмного канала дефлегматора из водоаммиачной паровой смеси. При этом предполагается известной температура стенки $T_{\text {cp }}$ вертикального канала дефлегматора и температура конденсации на поверхно- 
сти конденсата $T_{\text {гр }}$, а также температура и концентрация пароаммиачной смеси на входе в дефлегматор.

Дефлегматор представляет собой подъёмный канал (круглого сечения) частично теплоизолирован, а остальная часть канала охлаждается окружающим воздухом (рис. 2). В верхней части дефлегматора происходит конденсация паров воды и частично паров аммиака с образованием флегмы (слабый раствор аммиака в воде), которая в виде плёнки стекает вниз по внутренней поверхности канала в сборник слабого раствора генератора.

На выходе из дефлегматора необходимо обеспечить массовую долю аммиака $\xi_{\mathrm{NH} 3}=1$ или парциальное давление насыщения $p_{\mathrm{NH} 3}$, равное полному давлению в системе.

Рассмотрим задачу о ламинарной плёночной конденсации двухкомпонентного (водоаммиачного) пара на вертикальной стенке дефлегматора. Впервые задача о плёночной конденсации однокомпонентного пара была решена Нуссельтом.

На вертикальной стенке, температура которой $T_{\text {ср }}$ происходит конденсация паров смешивающихся жидкостей (рис. 2). Плёнка флегмы, толщину которой обозначим через $\delta=\delta(x)$, совершает ламинарное течение. При исследовании принимаются следующие общепринятые допущения [18]:

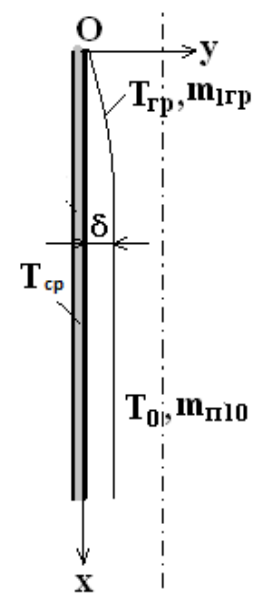

Рисунок 2 - Схема процесса тепломассообмена в вертикальном дефлегматоре

1) силы инерции, возникающие в плёнке конденсата, пренебрежимо малы по сравнению с силами вязкости и силами тяжести;

2) конвективный перенос теплоты в плёнке, а также теплопроводность вдоль неё несущественны по сравнению с теплопроводностью поперёк плёнки;

3) трение на границе раздела паровой и жидкой фаз учитывается посредством касательного напряжения со стороны газа $\tau_{r}$;

4) температура внешне поверхности плёнки конденсата постоянна и равна $\mathrm{T}_{\text {гр }}$;

5) физические параметры конденсата не зависят от температуры;
6) силы поверхностного натяжения на свободной поверхности плёнки не влияют на характер её течения;

7) плотность пара мала по сравнению с плотностью конденсата;

8) режим течения паровой смеси - развитый турбулентный и в ядре потока происходит идеальное радиальное перемешивание.

9) температуру стенки принимаем постоянной (Tcp) за счет интенсивного принудительного охлаждения.

Принятые допущения позволяют существенно упростить математическую формулировку задачи. Уравнение теплопроводности и движения имеют следующий вид [19]:

$$
\begin{gathered}
\frac{d^{2} T}{d y^{2}}=0, \\
\mu_{\varkappa} \frac{d^{2} V_{x}}{d y^{2}}=-\rho_{\varkappa} g,
\end{gathered}
$$

где $\mu_{ж}$ - динамическая вязкость флегмы, Па с;

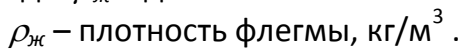

Граничные условия:

$$
\begin{gathered}
\text { при } y=0 \quad T=T_{c p}, V_{x}=0 ; \\
\text { при } y=\delta(x) \quad T=T_{2 p}, \mu_{\mathscr{⿰}} \frac{\partial V_{x}}{\partial y}=-\tau_{2},
\end{gathered}
$$

здесь $\tau_{2}$ - касательное напряжение на свободной поверхности $y=\delta(x)$ со стороны газа, $\mathrm{H} / \mathrm{m}^{2}$;

$$
\tau_{\mathrm{r}}=\frac{\xi \rho_{2} V_{2}^{2}}{8} ;
$$

$\rho_{2}$ - плотность газа, кг $/ \mathrm{M}^{3} ; \xi-$ гидравлический коэффициент трения, для безволновой поверхности тонкого слоя жидкости определяется по формуле Блазиуса (турбулентный поток газа)

$$
\xi=\frac{0,316}{\operatorname{Re}_{2}^{0.25}} ;
$$

число Рейнольдса по газу определяется соотношением (D- диаметр дефлегматора)

$$
R e_{2}=\frac{D V_{2}}{v_{2}} .
$$

Интегрирование уравнения теплопроводности (1) дает

$$
T(x, y)=a y+b .
$$

Из граничных условий (3)-(4) находим

$$
b=T_{c p}, \quad a=\frac{T_{2 p}-T_{c p}}{\delta(x)} .
$$

Таким образом, температура конденсата равна

$$
T(x, y)=\frac{T_{z p}-T_{c p}}{\delta(x)} y+T_{c p} .
$$

Локальный коэффициент теплоотдачи

$$
\alpha(x)=\frac{q_{c}}{T_{2 p}-T_{c p}}=\frac{\lambda_{\varkappa}\left(\frac{d T}{d y}\right)_{y=0}}{T_{2 p}-T_{c p}}=\frac{\lambda_{\varkappa}}{\delta(x)} .
$$


Интегрирование уравнения движения (2) с учетом граничных условий (3)-(4) даёт параболический профиль распределения продольной скорости

$$
V_{x}(x, y)=\frac{1}{\mu_{\varkappa}}\left(\rho_{\varkappa} g \delta(x)-\tau_{2}\right) y-\frac{\rho_{\varkappa} g}{2 \mu_{\varkappa}} y^{2}
$$

Средняя скорость течения конденсата $\bar{V}_{x}$ в сечении $x$ равна

$$
\bar{V}_{x}(x)=\frac{1}{\delta} \int_{0}^{\delta} V_{x} d y=\frac{\rho_{\varkappa} g}{3 \mu_{\varkappa}} \delta^{2}-\frac{\tau_{2}}{2 \mu_{\varkappa}} \delta .
$$

В уравнения (8)-(11) входят переменная толщина плёнки конденсата $\delta=\delta(x)$, причем увеличение толщины плёнки $\left(\frac{d \delta}{d x}>0\right)$ обусловлено непрерывным вдоль $x$ поступлением конденсата в плёнку. Если полагать, что теплота, отданная стенке, есть теплота фазового перехода, то приращение расхода плёнки на элементе $d x$ можно выразить следующим образом: $d G=\frac{q_{c}}{r} d x$, где $\frac{q_{c}}{r}=j_{2 p}-$ плотность потока массы,

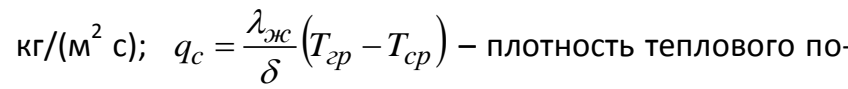
тока у стенки, Вт/м².

В результате

$$
d G=\frac{\lambda_{\varkappa}}{\delta} \frac{1}{r}\left(T_{2 p}-T_{c p}\right) .
$$

С другой стороны, изменение расхода конденсата можно описать выражением

$$
d G=d\left(\int_{0}^{\delta} \rho_{\varkappa} V_{x} d y\right)=d\left(\rho_{\varkappa} \bar{V}_{x} \delta\right)
$$

Из последних двух соотношений следует, что

$$
\frac{d}{d x}\left(\bar{V}_{x} \delta\right)=\frac{\lambda_{\mathscr{}}}{r \delta \rho_{\mathscr{K}}}\left(T_{z p}-T_{c p}\right) .
$$

Подставляя в это выражение значение средней скорости $\bar{V}_{x}$ из (11), получаем следующее дифференциальное уравнение относительно переменной толщины плёнки конденсата $\delta=\delta(x)$

$$
\delta^{2}\left(\delta-\frac{\tau_{2}}{\rho_{\varkappa} g}\right) \frac{d \delta}{d x}=\frac{\lambda_{\varkappa} \mu_{\varkappa}}{r \rho_{\varkappa}^{2} g}\left(T_{г p}-T_{c p}\right) .
$$

Начальное условие для уравнения (12) имеет вид:

при $x=0 \quad \delta=0$.

Приведем задачу (12)-(13) к безразмерному виду. Вводится линейный масштаб

$$
l=\sqrt[3]{\frac{\lambda_{\varkappa} \mu_{\varkappa}}{r \rho_{\varkappa}^{2} g} T_{2 p}}, \mathrm{M}
$$

и безразмерные величины

$$
\bar{\delta}=\frac{\delta}{l}, \quad \bar{x}=\frac{x}{l}, \quad \bar{T}_{c}=\frac{T_{c p}}{T_{2 p}}, \bar{\tau}_{2}=\frac{\tau_{2}}{\rho_{\varkappa} g l} .
$$

Дифференциальная задача (12)-(13) в безразмерной форме примет вид:

$$
\left\{\begin{array}{l}
\bar{\delta}^{2}\left(\bar{\delta}-\bar{\tau}_{2}\right) \frac{d \bar{\delta}}{d \bar{x}}=1-\bar{T}_{c p} \\
n p u \quad \bar{x}=0 \quad \bar{\delta}=0
\end{array} .\right.
$$

Решение задачи (16) представляется зависимоСтью

$$
\bar{\delta}^{4}(x)-\frac{4}{3} \bar{\tau}_{2} \bar{\delta}^{3}(x)-4\left(1-\bar{T}_{c p}\right) x=0 .
$$

Рассмотренная задача о ламинарной плёночной конденсации смешивающихся жидкостей не является завершённой, поскольку конденсируемая плёнка флегмы представляет смесь воды и аммиака. Теплофизические свойства флегмы $\lambda_{*}, \rho_{*}, \mu_{*}, r$, а также температура на поверхности конденсата $T_{2 p}$ являются неизвестными, так как эти величины зависят от концентрации каждого компонента флегмы.

В связи с этим необходимо проанализировать процессы переноса в смеси паров происходящих в ядре потока дефлегматора. Следует иметь в виду, что водоаммиачный пар во всём объёме на значительном расстоянии от поверхности разрыва является насыщенным, его температура и давление равны соответственно $T_{o}$ и $p$, соответствующие состоянию насыщения. В насыщенном состоянии находится также поверхность конденсата. Температуре поверхности раздела фаз $T_{2 p}$ соответствуют массовые доли в паре $m_{n 12 p}$ и $m_{n 2 г p}=1-m_{n 1 г p}$ и массовые доли в жидкости (флегме) $m_{ж 1 г p}$ и $m_{ж 2 г p}=1-m_{ж 1 г p}$. В общем случае $m_{n 12 p} \neq$ $m_{ж 12 p}$ и $m_{n 2 г p} \neq m_{ж 1 г p}$. Полагая, что $T_{2 p}=$ const приходим к постоянству вдоль поверхности разрыва концентраций $m_{ж 1 г p}$ и $m_{ж 2 г р}$, полагая также, что виде непроницаемости стенки можно считать, что концентрации $m_{ж 1}$ и $m_{ж 2}$ в жидкости всюду равны соответственно $m_{ж 1 г р}$ и $m_{ж 2 г р}$.

Проведем исследование процессов переноса в паровой фазе. Поля скоростей, температуры и конденсации аммиака в пограничных слоях описываются уравнениями [13]:

$$
\begin{aligned}
& V_{x} \frac{\partial V_{x}}{\partial x}+\frac{\partial V_{x}}{\partial x}+v_{y} \frac{\partial V_{x}}{\partial y}=g\left(1-\frac{\rho_{0}}{\rho}\right)+v \frac{\partial^{2} V_{x}}{\partial y^{2}}, \frac{\partial V_{x}}{\partial x}+\frac{\partial V_{y}}{\partial y}=0 \\
& V_{x} \frac{\partial T}{\partial x}+V_{y} \frac{\partial T}{\partial y}=a \frac{\partial^{2} T}{\partial y^{2}} \\
& V_{x} \frac{\partial m_{1}}{\partial x}+V_{y} \frac{\partial m_{1}}{\partial y}=D \frac{\partial^{2} m_{1}}{\partial y^{2}}
\end{aligned}
$$

Все физические свойства пара, входящие в эти уравнения, считаются постоянными, исключая плотность смеси $(\rho)$.

Полагая, что двухкомпонентная паровая смесь подчиняется уравнению состояния $p=Z \rho R T$, и коэффициент сжимаемости $Z$ равен $Z_{0}$, можно получить, что 


$$
\begin{aligned}
& 1-\frac{\rho_{0}}{\rho}=A_{m} \frac{m_{n 1}-m_{n 10}}{m_{n 12 p}-m_{n 10}}+A_{T} \frac{T-T_{0}}{T_{2 p}-T_{0}}- \\
& -A_{m} A_{T} \frac{m_{n 1}-m_{n 10}}{m_{n 12 p}-m_{n 10}} \cdot \frac{T-T_{0}}{T_{2 p}-T_{0}}
\end{aligned},
$$

где $A_{m}=\frac{\left(M_{1}-M_{2}\right)\left(m_{n 12 p}-m_{n 10}\right)}{M_{1}-m_{n 10}\left(M_{1}-M_{2}\right)} ; A_{T}=\frac{T_{0}-T_{z p}}{T_{0}}$,

$M$ - молекулярная масса компонентов смеси.

Уравнения (18) допускает преобразование этих уравнений в частных производных к системе обыкновенных дифференциальных уравнений.

Вводится независимая переменная (автомодельное преобразование)

$$
\eta=\frac{c(y-\delta)}{x^{1 / 4}}, \text { где с }=\left(g A_{m} / 4 v^{2}\right)^{1 / 4} .
$$

Вводятся также новые неизвестные функции

$$
\begin{gathered}
f(\eta)=\frac{\psi}{4 c v x^{3 / 4}}, \\
\psi-\text { функция тока }\left(V_{x}=\frac{\partial \psi}{\partial y}, \quad V_{y}=-\frac{\partial \psi}{\partial x}\right) \\
\varphi(\eta)=\frac{m_{n 1}-m_{n 10}}{m_{n z p}-m_{n 10}}, \\
\theta(\eta)=\frac{T_{0}-T}{T_{0}-T_{2 p}} .
\end{gathered}
$$

В результате, уравнения (18) в новых переменных приводятся к системе

$$
\begin{gathered}
f^{\prime \prime \prime}+3 f f^{\prime \prime}-2\left(f^{\prime}\right)^{2}+\varphi+\theta \frac{A_{T}}{A_{m}}-\varphi \theta A_{T}=0, \\
\varphi^{\prime \prime}+3 \operatorname{Pr}_{D} f \varphi^{\prime}=0, \\
\theta^{\prime \prime}+3 \operatorname{Pr} f \theta^{\prime}=0 .
\end{gathered}
$$

Ниже приведены результаты расчета вертикального дефлегматора абсорбционной водоаммиачной холодильной машины с поджимающим бустеркомпрессором и холодопроизводительностью 1000 Вт при температуре испарения $0^{\circ} \mathrm{C}$ и давлении 0,4 МПа.

Условия охлаждения (отвода тепла дефлегмации) интенсивная вынужденная конвекция.

С учетом приведенных выше модельных представлений выполнен расчет параметров течения флегмы и паровой смеси в вертикальном дефлегматоре.

Исходные данные для расчета:

а) холодопроизводительность $1000 \mathrm{Bт}$;

б) температура(давление) кипения в испарителе $0^{\circ} \mathrm{C}$ (0,4МПа);

в) давление в генераторе - $1 \mathrm{MПа;}$

г) температура окружающего воздуха $32^{\circ} \mathrm{C}$;

д) температура паровой смеси на входе (выходе) в дефлегматор $100(40)^{\circ} \mathrm{C}$

е) высота дефлегматора -1,0 м.

Результаты расчетов приведены на рисунках 3-7.

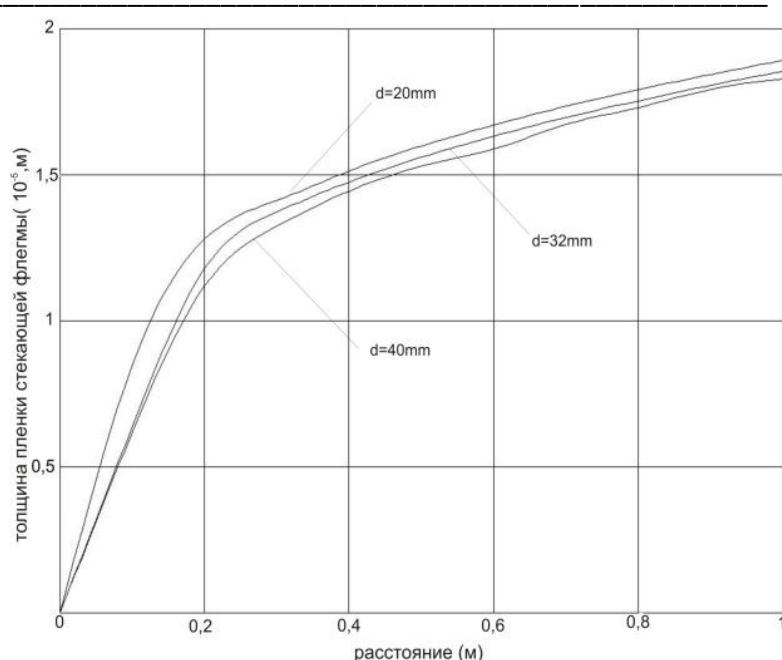

Рисунок 3 - Изменение толщины пленки стекающей фрлегмы по высоте вертикального десрлегматора для различных внутренних диаметров (0-верхняя часть)

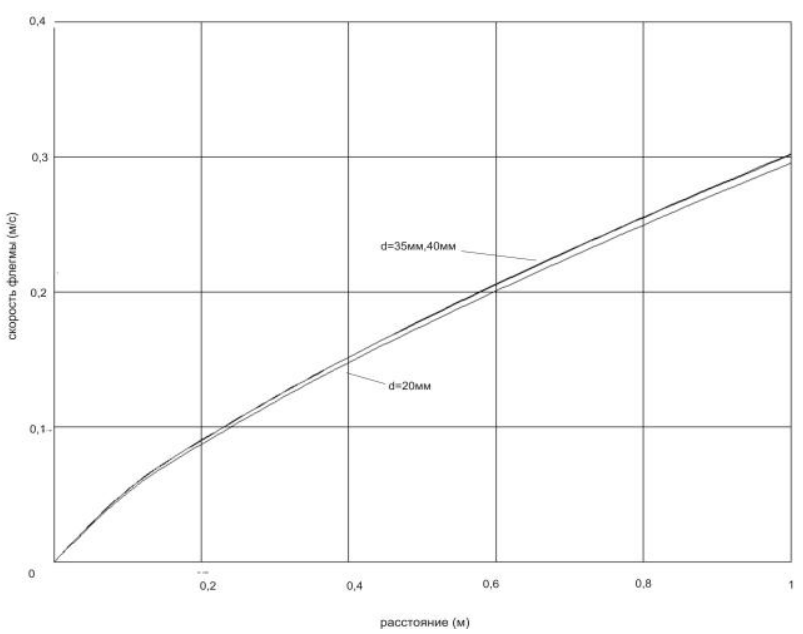

a)

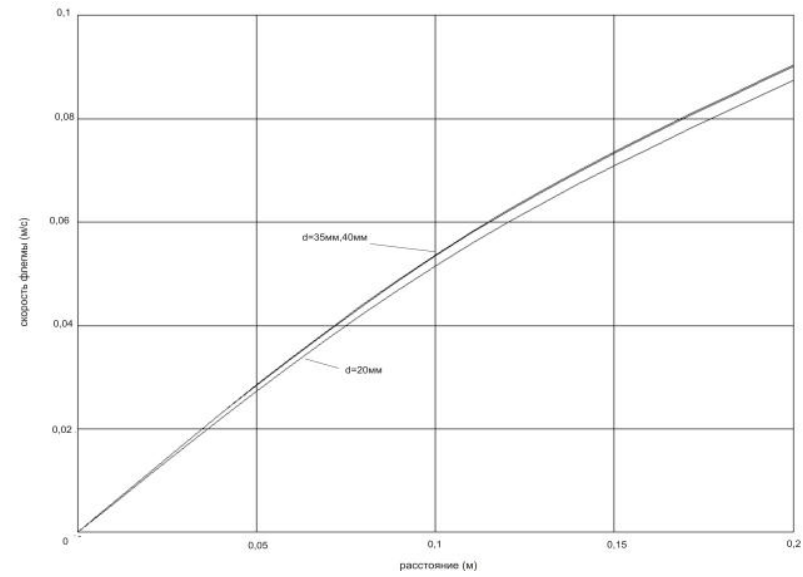

б)

Рисунок 4 - Изменение скорости стекающей флегмы по высоте вертикального деслегматора для различных внутренних диаметров (0-верхняя часть)

$a$ - распределение скорости по всей длине дефлегматора; б - распределение скорости на начальном участке дерлегматора 


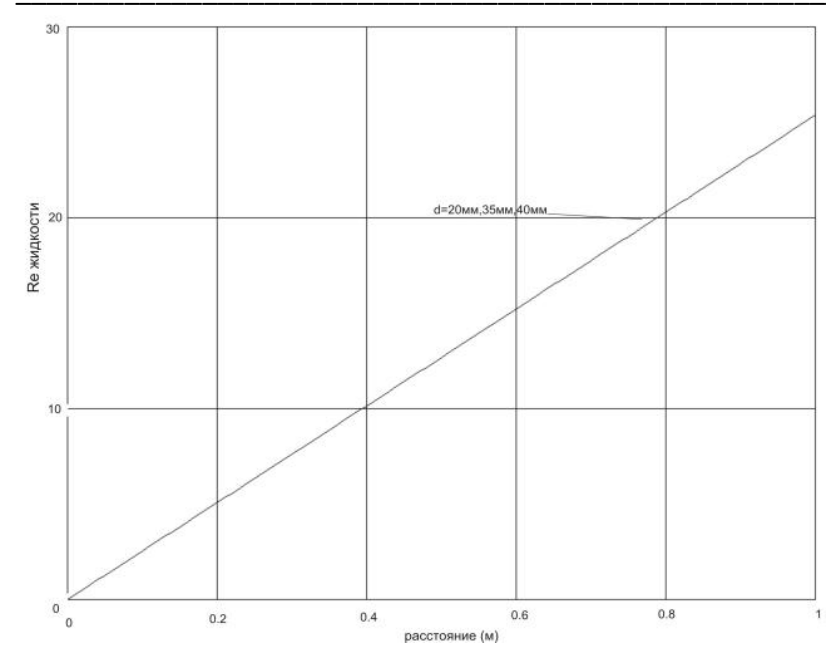

Рисунок 5 - Изменение числа Рейнольдса стекающей фллегмы по высоте вертикального дефлегматора для различных внутренних диаметров (0-верхняя часть)

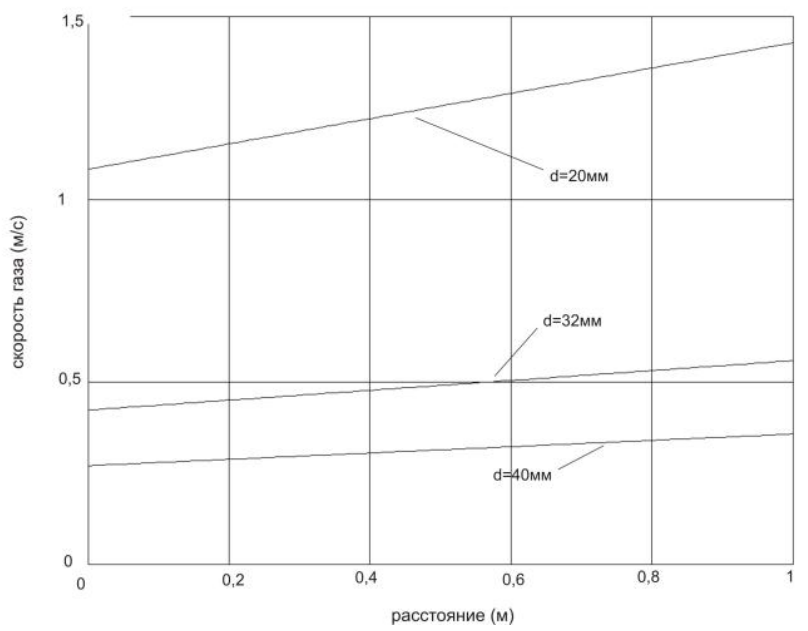

Рисунок 6 - Изменение скорости паровой смеси по высоте вертикального дефлегматора для различных внутренних диаметров (0 - верхняя часть)

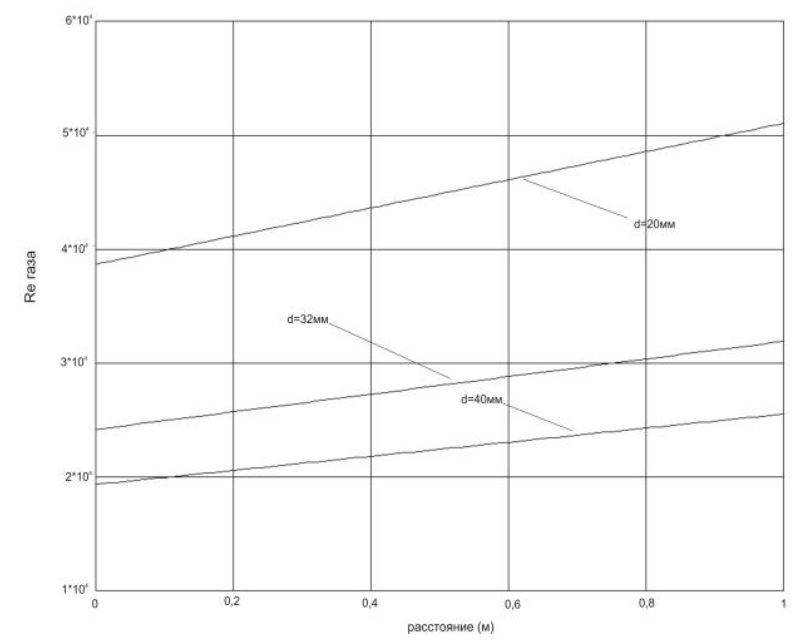

Рисунок 7-Изменение числа Рейнольдса паровой смеси по высоте вертикального дерлегматора для различных внутренних диаметров (0-верхняя часть)

\section{Выводы}

1. Приведенная модель расчета гидравлических параметров пленочного течения с восходящим потоком паровой смеси является развитием аналогичной модели, выполненной для условий естественноконвективного охлаждения теплорассеивающей поверхности дефлегматора и отличается высокоэффективным отводом тепла в режиме вынужденной конвекции.

2. Модель позволила оценить параметры пленочного течения жидкости и парового потока (скорости и числа Рейнольдса) для типичных значений диаметров труб дефлегматора 20, 32 и 40 мм.

3. Показано, что: а) режим пленочного течения ламинарный, а парового потока - развитый турбулентный; б) толщина пленки практически неизменна для рассматриваемых размеров труб дефлегматора.

4. Толщина пленки по всей высоте дефлегматора не оказывает практического влияния на термическое сопротивление процесса теплопередачи в вертикальном дефлегматоре в рассматриваемом диапазоне параметров и размеров.

\section{Литература}

1. Алексеев В.В., Чекарев К.В. Получение пресной воды из влажного воздуха [Текст] // Аридные экосистемы. - 1996. - Т. 2. - № 2-3. С. 123-130

2. Перельштейн Б.Х. Новые энергетические системы [Текст]: монография / Б.Х. Перельштейн ; Казань: Издво Казан. гос. техн. ун-та, 2008. - 244 с.

3. Titlov O. Optimizing Nh3-H2o Absorption System To Produce Water From Ambient Air / O. Titlov, Yu. Baidak, M. Khmelnyuk // Applied Science Report (ASR). - 2015. V. 10. - N. 2. - P.91-100.

4. Осадчук Е.А. Разработка схем насосных и безнасосных абсорбционных водоаммиачных холодильных машин для работы в системах получения воды из атмосферного воздуха / Е.А. Осадчук, А.С. Титлов, В.М. Кузаконь, Г.В. Шлапак // Технологический аудит и резервы производства. - 2015. - № 3/3(23). - С. 30-37. DOI: 10.15587/2312-8372.2015.44139.

5. Галимова Л.В. Абсорбционные холодильные машины и тепловые насосы [Текст] : монография / Л.В. Галимова. - Астрахань: Изд-во АГТУ, 1997. - 226 с.

6. Патент на корисну модель № 104853 Україна, МПК Е03В 3/28 (2006.1), F25B 15/10 (2006.1). Установка для одержання води з атмосферного повітря / О.Б. Василів, О.С. Тітлов, Є.О. Осадчук, В.М. Кузаконь (Україна). - № u 2015 07385; заявл. 23.07.2015; опубл. 25.02.2016, Бюл. № 4.

7. Патент на корисну модель № 104854 Україна, МПК Е03B 3/28 (2006.1), F25B 15/10 (2006.1). Спосіб одержання води з атмосферного повітря / О.Б. Василів, О.С. Тітлов, Є.О. Осадчук, В.М. Кузаконь (Україна). - № u 2015 07386; заявл. 23.07.2015; опубл. 25.02.2016, Бюл. № 4. 
8. Патент на корисну модель № 100195 Україна, МПК(2015.01) E03B 3/28 (2006.1), F25B 15/00. Спосіб одержання води з атмосферного повітря / О.Б. Василів, О.С. Тітлов, Є.О. Осадчук (Україна). - № u201501512; заявл. 20.02.2015; опубл. 10.07.2015, Бюл. № 9.

9. Ищенко И.Н. Моделирование циклов насосных и безнасосных абсорбционных холодильных агрегатов / И.Н. Ищенко // Наукові праці Одеської національної академії харчових технологій. - 2010. - № 38. - Т. 2. - С. 393-404.

10. Titlov A.S. The search of the water-ammonia absorption refrigeration machines' energy efficient modes / A. S. Titlov, E.A. Osadchuk // IX Minsk International Seminar "Heat Pipes, Heat Pumps, Refrigerators, Power Sources”, Minsk, Belarus, 07-10 September, 2015. - P. 309314.

11. Осадчук Е.А. Поиск энергетически эффективных режимов работы абсорбционной водоаммиачной холодильной машины в системах получения воды из атмосферного воздуха / Е.А.Осадчук, А.С.Титлов, О.Б.Васылив, С.Ю.Мазуренко // Наукові праці ОНАХТ. 2014. - № 45. - Т.1. - С. 65-69.

12. Богданов С.Н., Бурцев С.И., Иванов О.П., Куприянова А.В. Холодильная техника. Кондиционирование воздуха. Свойства веществ: Справ./Под ред. С.Н.Богданова. -4-е изд., перераб. и доп. - СПб.: СПбГАХПТ, 1999. -320 с.

13. Бабакин Б.С., Выгодин В.А. Бытовые холодильники и морозильники /2-е изд., испр. и доп. -М.: Колос, 2000. -656 с.

14. Титлов А.С. Научно-технические основы создания энергосберегающих бытовых абсорбционных холодильных приборов: дис...д-ра техн. наук: 05.05.14 / Титлов Александр Сергеевич. - Одесса, 2008. - 447 с.

15. Пат. №2350857 Российская Федерация, МПК F 25 В 15/10. Способ работы абсорбционного холодильного агрегата / В.В. Ильиных (Россия), А.С. Титлов (Украина), Д.Н. Ивакин., Г.И. Овечкин, А.А. Кишкин (Россия). - № 2007116257/06; заявл. 28.04.2007; опубл. 27.03.2009, Бюл. № 9.

16. Пат. на корисну модель № 30771 F Україна, МПК F 25 В 15/00. Спосіб автоматичного керування абсорбційними холодильними приладами / Тітлова О.О., Хобін В.А.; заявник та патентовласник ОНАХТ. - № 200712763 ; заявл. 19.11.07 ; опубл. 11.03.08. Бюл. №5.

17. Очеретяный Ю.А. Исследование влияния качки судна на процессы гравитационного пленочного течения рабочего тела в теплообменных элементах абсорбционных холодильных агрегатов (AXA) / Ю.А.Очеретяный, В.Х.Кирилов, А.С.Титлов // Наукові праці ОНАХТ/ Мін-во освіти і науки України. Одеса:2010 - Вип.38 - Т.2. - С.365-372.

18. Очеретяный Ю.А. Моделирование процессов тепломассообмена генераторных узлов абсорбционных холодильных агрегатов (AXА) / Ю.А.Очеретяный, В.Х.Кирилов, А.С.Титлов // Наукові праці ОНАХТ/ Мін-во освіти і науки України. - Одеса:2010 - Вип.38 - Т.2. С.372-378.

19. Кириллов В.Х. Компьютерное моделирование физических и технологических процессов. Теория, алгоритмы, программы / В.Х. Кириллов, В.В. Зуб, А.С. Титлов, А.К. Ширшков // Учебное пособие. - Одесса: Издательство ВМВ, 2016. - 565 с.

\title{
Mathematical Simulation of Operating Modes of Absorption Water- Ammonia Refrigeration Unit Rectifier in the Systems for Producing Water from Atmospheric Air Using Solar Energy
}

\author{
E. A. Osadchuk, V. Kh. Kirilov \\ Odessa National Academy of Food Technologies, 112 Kanatnaya st., Odessa, 65039, Ukraine
}

\begin{abstract}
The mathematical model of film flow modes with an upward flow of a steam mixture with a highly efficient heat removal in the forced convection mode has been developed. The parameters of the liquid film flow and the vapor flow (velocity and Reynolds number) were estimated for typical values of rectifier tubes diameters in 20, $32 \mathrm{and} 40 \mathrm{~mm}$. It was shown that the mode of film flow is laminar; of the steam flow - developed turbulent, and the thickness of the film is practically unchanged for the rectifier tubes dimensions under consideration.
\end{abstract}

Key words: Film Flow Along the Vertical Wall of the Rectifier; Absorption Water-Ammonia Refrigeration Unit; Solar Collector.

\section{References}

1. Alekseev, V.V., Chekarev, K.V. (1996) Obtaining of Fresh Water of Humid Air. Arid ecosystems, Vol.2, No.2-3, 123-130 (in Russian)
2. Perelshteyn, B.H. (2008) New Energy Systems: monograph. Kazan, 244 p. (in Russian)

3. Titlov, O. Baidak Yu., Khmelnyuk M. (2015) Optimizing Nh3-H2o Absorption System to Produce Water From 
Ambient Air. Applied Science Reports, 10(2), 91-100. DOI: https://doi.org/10.15192/pscp.asr.2015.10.2.9099

4. Osadchuk, E.A., Titlov, A.S., Kuzakon, V.M., Shlapak, G.V. (2015) development of schemes of pump and gasoline-pump absorption water-ammonia refrigeration machines to work in a system of water production from the air. Technology audit and production reserves, 3(3), 30-37. (in Russian) DOI: 10.15587/2312-8372.2015.44139

5. Galimova L.V. (1997) Absorption chillers and heat pumps: monograph. Astrahan, 226 p. (in Russian)

6. Vasillv, O.B., TItlov, O.S., Osadchuk, E.O., Kuzakon, V.M. The patent for useful model No. 104853 Ukraine, MPK EO3B 3/28 (2006.1), F25B 15/10 (2006.1). A plant for producing water from atmospheric air. No. u 2015 07385; stated 23.07.2015; published 25.02.2016, newsletter No. 4.

7. Vasillv, O.B., TItlov, O.S., Osadchuk, E.O., Kuzakon, V.M. The patent for useful model No.104854 Ukraine, MPK E03B 3/28 (2006.1), F25B 15/10 (2006.1). Method for producing water from atmospheric air No.u 2015 07386; stated 23.07.2015; published 25.02.2016, newsletter No.4. 8. Vasillv, O.B., TItlov, O.S., Osadchuk, E.O.The patent for useful model No.100195 Ukraine, MPK (2015.01) E03B 3/28 (2006.1), F25B 15/00. Method for producing water from atmospheric air. No.u201501512; stated 20.02.2015; published 10.07.2015, newsletter No.9.

9. Ischenko, I.N. (2010) Simulation of pumping cycles and pumpless absorption refrigeration units. Research works, No.38, Vol.2, 393-404.

10. Titlov, A.S., Osadchuk, E.A. (2015) The search of the water-ammonia absorption refrigeration machines' energy efficient modes. IX Minsk International Seminar "Heat Pipes, Heat Pumps, Refrigerators, Power Sources", Minsk, Belarus, 07-10 Sep 2015, 309-314.

11. Osadchuk, E.A., Titlov, A.S., Vasyiliv, O.B., Mazurenko, S.Yu. (2014) Search energy efficient modes waterammonia absorption refrigerating machine in the system for producing water from atmospheric air Research works, No. 45, Vol.1, 65-69. (in Russian)
12. Bogdanov, S.N., Burtsev, S.I., Ivanov, O.P., Kupriyanova, A.V. (1999) Refrigeration. Air conditioning. Properties of substances. Ed. S.N. Bogdanova. 4th edition, 320 p. (in Russian)

13. Babakin, B.S., Vyigodin, V.A. (2000) Household refrigerators and freezers. 2-nd edition, revised and enlarged, Kolos, 656 p. (in Russian)

14. Titlov, A.S. (2008) Scientific and technical basis for energy saving of domestic absorption refrigeration devices: thesis of doctor of technical Sciences 05.05.14. Odessa, 447 p. (in Russian)

15. Patent No.2350857 Russian Federation, MPK F 25 B 15/10. A method of operating an absorption refrigeration unit / V.V. Ilinyih (Russia), A.S. Titlov (Ukraine), D.N. Ivakin., G.I. Ovechkin, A.A. Kishkin (Russia).- No.2007116257/06; stated 28.04.2007; published 27.03.2009, newsletter No. 9. 16. The patent for useful model No. $30771 \mathrm{~F}$ Ukraine, MPK $F$ 25B 15/00. Method of automatic control absorption refrigeration devices / O.O. TItlova, V.A. Hobin; applicant and patentee ONAFT.- No.200712763; stated 19.11.07 ; published 11.03.08, newsletter No.5. (in Russian)

17. Ocheretyanyiy, Yu.A., Kirilov, V.H., Titlov, A.S. (2010) Study of the influence of ship motions on the process of gravitational film flow of the working fluid in the heat exchange elements of the absorption refrigeration units. Research works, Vol.2, 365-372. (in Russian)

18. Ocheretyanyiy, Yu.A., Kirilov, V.H., Titlov, A.S. (2010) Modeling of processes of heat and mass transfer in generator of nodes in absorption refrigeration units. Research works, Vol.2, 372-378. (in Russian)

19. Kirillov, V.H., Zub, V.V., Titlov, A.S., Shirshkov, A.K. (2016) Computer simulation of physical and technological processes. Theory, algorithms, programs. Publishing House BMB, 565 p. (in Russian)

Received 12 December 2016 Approved 07 February 2017 Available in Internet 17 March 2017 